\title{
Novel glycolipid agents for killing cisplatin- resistant human epithelial ovarian cancer cells
}

\author{
Amani I. Moraya', Jennifer L. Ali', Pranati Samadder', Lisa Liang' ${ }^{1}$, Ludivine Coudière Morrison', \\ Tamra E. Werbowetski-Ogilvie ${ }^{1}$, Makanjuola Ogunsina², Frank Schweizer², Gilbert Arthur ${ }^{1}$ \\ and Mark W. Nachtigal ${ }^{1,3,4,5^{*}}$
}

\begin{abstract}
Background: Chemotherapy resistance is one of the major factors contributing to mortality from human epithelial ovarian cancer (EOC). Identifying drugs that can effectively kill chemotherapy-resistant EOC cells would be a major advance in reducing mortality. Glycosylated antitumour ether lipids (GAELs) are synthetic glycolipids that are cytotoxic to a wide range of cancer cells. They appear to induce cancer cell death in an apoptosis-independent manner.

Methods: Herein, the effectiveness of two GAELs, GLN and MO-101, in killing chemotherapy-sensitive and -resistant EOC cells lines and primary cell samples was tested using monolayer, non-adherent aggregate, and non-adherent spheroid cultures.

Results: Our results show that EOC cells exhibit a differential sensitivity to the GAELs. Strikingly, both GAELs are capable of inducing EOC cell death in chemotherapy-sensitive and -resistant cells grown as monolayer or nonadherent cultures. Mechanistic studies provide evidence that apoptotic-cell death (caspase activation) contributes to, but is not completely responsible for, GAEL-induced cell killing in the A2780-cp EOC cell line, but not primary EOC cell samples.
\end{abstract}

Conclusions: Studies using primary EOC cell samples supports previously published work showing a GAEL-induced caspase-independent mechanism of death. GAELs hold promise for development as novel compounds to combat EOC mortality due to chemotherapy resistance.

Keywords: Ovarian cancer, Drug-resistance, Glycosylated anti-tumour ether lipid, Spheroid

\section{Background}

Chemotherapy resistance of epithelial ovarian cancer (EOC) cells is a major contributor to reducing the survival rate among EOC patients [1-3]. EOCs are typically treated by surgically debulking the pelvic disease and with chemotherapy [2]. While the majority of patients respond to initial chemotherapy usually comprising 6-9 cycles of a platinum agent (carboplatin) and a taxane, up to $75 \%$ of EOC patients will relapse within 18 months with chemotherapy-resistant disease $[4,5]$. Therefore,

\footnotetext{
* Correspondence: mark.nachtigal@umanitoba.ca

'Dept. of Biochemistry \& Medical Genetics, University of Manitoba, Room 333 BMSB, 745 Bannatyne Avenue, Winnipeg R3E 0 W9, MB, Canada

${ }^{3}$ Dept. of Obstetrics, Gynecology \& Reproductive Sciences, University of

Manitoba, Winnipeg, Canada

Full list of author information is available at the end of the article
}

there is an unmet clinical need to improve the treatment of patients with recurrent, drug resistant EOC.

Chemoresistance is defined clinically by disease recurrence less than six months after initial treatment. Recurrent disease is treated with drugs such as gemcitabine, liposomal doxorubicin, or topotecan, which have been shown to increase progression-free survival by $10-30 \%$ in platinum-resistant EOC $[2,6]$. Presently, recurrent EOC is essentially an incurable disease. Thus, evaluating novel drug treatments using models of chemotherapy resistant disease becomes critical to improve outcome for this patient population.

Monolayer culture systems have provided a wealth of information about cancer cell biology, but there is recognition of the limitations of this system and its relevance 
to in vivo cell biology [7-9]. Although, the majority of the literature has used the two-dimensional monolayer system as a model for testing anti-cancer therapies, the success of treatment in clinical trials is only approximately 5\% [10]. While the monolayer system often shows promising results with experimental compounds in vitro, these activities often fail in vivo. Three-dimensional or non-adherent culture systems are considered more representative of in vivo conditions, typically using culture plastics that do not promote cell adhesion (non-adherent cultures) or hanging droplet techniques resulting in loose cell aggregates or spheroid formation [7-9, 11-13]. Importantly, cells in non-adherent cultures exhibited frequently higher levels of chemoresistance compared to adherent conditions [ 9 , 14-16]. Testing drug treatments using these systems will likely decrease the gap between laboratory research and clinical trials.

Current efforts to kill EOC cancer cells is mostly based on damaging the DNA, preventing DNA synthesis, or targeting the cell cycle to stop cell proliferation. Targeting these biological events activates apoptotic pathways that induce cell death. However, EOC cells are either inherently resistant or capable of developing resistance during chemotherapy treatment by various pathways to evade apoptosis [3, 12, 17-22]. Glycosylated antitumour ether lipids (GAELs) are synthetic small molecular weight amphiphilic glycolipids that are cytotoxic to a wide range of cancer cells [23, 24]. However, there has been little research investigating the effects of GAELs on EOC cells [25]. The prototypical GAEL, containing a 2-amino-glucose head group (GLN; 1-O-hexadecyl-2-O-methyl-3-O-(2'-amino-2' deoxy- $\beta$-D-glucopyranosyl)-sn-glycerol) kills cells by an apoptosis-independent mechanism [26, 27]. GAELs exhibited a distinct mechanism of action from other antitumour ether lipids and current anti-cancer agents, and there is evidence GAELs enter cancer cells via an endocytic pathway, which leads to the generation of large acidic vacuoles and the release of acid hydrolases, including cathepsin $\mathrm{D}$, that induce a caspase-independent form of cell death [23, 28]. We have recently reported that GAELs not only inhibited spheroid formation by tumour propagating cells derived from breast cancer cell lines, but they also caused the disintegration of tumour propagating cell spheroids and killed the cells [28].

There are few reliable models of drug-resistant EOC cells available for research $[7,12,29]$. The two most popular are (A) A2780-s (sensitive) and A2780-cp (cisplatin resistant) isogenic cell lines representing the endometrioid subtype of EOC [30], and (B) PE01 and PE04 cells established from the ascites of a patient with poorly differentiated serous adenocarcinoma before/after development of clinical resistance. As an alternative to these immortalized cell lines, investigators use primary
EOC cell samples isolated from solid tumours or ascites before and after manifestation of clinical resistance. Herein, we used the A2780-s/A2780-cp cell lines and primary cells from seven different EOC patients to test the effect of GAELs on EOC cell viability. Moreover, the GAEL effects were tested on cells grown as adherent monolayers, and non-adherent cellular aggregates or spheroids. Experiments were performed to study the effect of GLN and the most active GAEL we have synthesized to date, 1-O-Hexadecyl-2-O-methyl-3-O(2,6'-diamino-2,'6'-dideoxy-a-D-glucopyranosyl)-sn-glyce rol (MO-101), on the cell viability of these different platinum-resistant models of EOC. The differences between the two structurally similar GAELs is the presence of two cationic (NH2) groups in MO-101 while GLN has only one cationic group. As GLN and MO-101 effectively killed platinum-sensitive and platinum-resistance EOC cells, investigations were conducted to provide insight into putative mechanisms of action for these drugs in EOC cells. Our results support further investigation of GAELs as novel agents for the treatment of recurrent, platinum-resistant ovarian cancer.

\section{Methods}

Cell Culture. Primary human EOC cells were isolated from ascites fluid obtained from patients with ovarian adenocarcinoma (for patient characteristics, see Additional file 1: Table S1), and grown as previously described [31, 32]. All experiments with primary EOC cells were performed between passages 1 and 3. The A2780-s and A2780-cp endometrioid EOC cell lines were obtained from Dr. B. Tsang (University of Ottawa), and were authenticated by short tandem repeat profiling in June 2016 using the Promega PowerPlex system (ATCC cell authentication service). The COV362 cell line (passage 36; ECACC catalog \# 07071904) was purchased from Sigma-Aldrich. Cells were maintained without antibiotics in DMEM/F12 + fetal bovine serum $(10 \% \mathrm{v} / \mathrm{v})$. For experiments with non-adherent cultures, cells were seeded from adherent cultures into ultralow attachment plates (Greiner Bio-One CELLSTAR ${ }^{\circ}$ Cell-Repellent Surface Microplate \# 655970) for $48 \mathrm{~h}$ (h) prior to drug treatment. All cells were maintained at $37{ }^{\circ} \mathrm{C}, 5 \% \mathrm{CO}_{2} /$ 95\% air, 100\% humidity.

Drugs. Glycosylated antitumor ether lipids (GAELs), specifically GLN and MO-101 (compound 2) were synthesized as described in Ogunsina et. al [33]. Structurally GLN and MO-101 differ by introduction of an amino substitution at the $\mathrm{C}_{6}$-position of glucose and the nature of the anomeric linkage (Additional file 2: Figure S1). Cisplatin (Tocris Bioscience), Q-VD-OPh (pan-caspase inhibitor, APExBio), and staurosporine were reconstituted in 100\% dimethyl sulfoxide (DMSO). The GAELs and pepstatin A (acid protease/ 
cathepsin D inhibitor) were reconstituted in 95\% ethanol. DMSO and ethanol were used as vehicle controls where applicable.

Cell viability. Adherent cultures: Cells were seeded at 4000 cells/well in 96-well plates and grown for $24 \mathrm{~h}$ before adding drugs. Cells were treated with cisplatin (DMSO vehicle control) or with GAELs (95\% ethanol vehicle control) for the times indicated. The concentrations of ethanol did not exceed $0.1 \%(\mathrm{v} / \mathrm{v})$. Non-adherent cultures: Cells were seeded at 10000 cells/well in 96well ultralow attachment plates and allowed to form aggregates or spheroids for $48 \mathrm{~h}$ prior to drug treatment.

To assess viability, Cell Titer 96 Aqueous One Solution Reagent (Promega Corporation, G3580), was added to each well and incubated for $1-4 \mathrm{~h}$ at $37{ }^{\circ} \mathrm{C}$. Absorbance was read at $490 \mathrm{~nm}$ with a SpectraMax M2 ${ }^{\mathrm{e}}$ (Molecular Devices) and the quantity of formazan product being directly proportional to the number of viable cells.

Caspase-Dependent Cell Death Assay. Cells were plated in either 96-well or 24-well ultralow attachment plates and allowed to grow for $48 \mathrm{~h}$ prior to drug treatment. Cells were pre-treated for $4 \mathrm{~h}$ with the pancaspase inhibitor Q-VD-OPh (QVD; $25 \mu \mathrm{M})$ followed by addition of MO-101, GLN or cisplatin with the inhibitor for $48 \mathrm{~h}$. Cells were analyzed for viability using Cell Titer 96 Aqueous One Solution Reagent or by flow cytometry using the CaspGLOW Fluorescein Active Caspase Staining kit (BioVision Inc., K180-100) to detect activated caspases. For these experiments, additional cell viability data was determined by trypan blue exclusion and measured using a BioRad TC-20 Automated Cell Counter.

Flow cytometry measurement. Cell viability was assessed using an APC Annexin V staining kit (BD Pharmigen, 559763). A2780cp cells were plated into 24well ultralow attachment plates and allowed to grow for $48 \mathrm{~h}$ prior to drug addition. Cells were treated with MO-101 (7.5, 12.5 or $15 \mu \mathrm{M})$, GLN $(15,20$, or $25 \mu \mathrm{M})$, or vehicle control for $48 \mathrm{~h}$. Cells were dissociated with Accutase and a single cell suspension at a density of $1 \times 10^{5}$ cells $/ \mathrm{ml}$ was stained simultaneously with Annexin V-APC and 7-amino actinomycin D (7-AAD) using concentrations of $1 \mu \mathrm{l} / 100000$ cells and $2 \mu \mathrm{l} / 100$ 000 cells, respectively. Samples were incubated for $15 \mathrm{~min}$ and then resuspended in $400 \mu \mathrm{l}$ of $1 \times$ Binding Buffer. Flow cytometry was performed on a Gallios ${ }^{\mathrm{Tu}}$ flow cytometer and analyzed using Kaluza analysis software (Beckman Coulter, Inc.).

To assess cell cycle, A2780cp cells were plated into 24-well ultralow attachment plates and allowed to grow for $48 \mathrm{~h}$ prior to drug addition. Cells were treated with MO-101 $(5,7.5,12.5$ or $15 \mu \mathrm{M})$, GLN $(10,25 \mu \mathrm{M})$, or vehicle control for $48 \mathrm{~h}$. Prior to harvesting, cells were pulsed for $3 \mathrm{~h}$ at $37{ }^{\circ} \mathrm{C}$ with $1 \mathrm{mM}$ bromo-deoxyuridine (BrdU, $10 \mu \mathrm{M})$. BrdU was detected with anti-
BrdU-APC using the APC BrdU Flow Kit (BD Pharmingen, 552598) according to manufacturer's guidelines. Cells were then counterstained with 7-AAD and flow data acquisition was performed on the MoFloXDP (Beckman Coulter, Inc.). 400000 cells per condition were analyzed from a minimum of three independent experiments.

Statistical Analyses. One way ANOVA with Dunnett's multiple comparison test were conducted for drug treatment experiments. Unless otherwise stated, the $p$ values represent data from three independent experiments conducted in sextuplicate. Flow cytometry data represents three independent experiments.

\section{Results}

Cisplatin sensitivity of adherent vs. non-adherent EOC cultures

While cell spheroids may be observed in malignant ascites, our laboratory more frequently observes single EOC cells and loose cell aggregates (Additional file 3: Figure S2). The model used for the non-adherent culture experiments conducted herein comprise a model system of cellular aggregates, although some cell samples efficiently form spheroids under these conditions, e.g. EOC013F and EOC061 (Additional file 4: Figure S3). The A2780-s (cisplatin sensitive) and A2780-cp (cisplatin resistant) cell lines, in addition to several primary EOC cell samples (Additional file 1: Table S1), were grown as adherent monolayers, non-adherent aggregates or spheroids. Cell viability in response to cisplatin or two different GAEL compounds, GLN or MO-101, was assessed.

A2780-s cells were quite sensitive to cisplatin treatment $\left(\mathrm{CC}_{50} \sim 5-7 \mu \mathrm{M}\right)$ with little difference in the cisplatin sensitivity between the cells grown in adherent or non-adherent conditions (Fig. 1a). Concentrations of $25 \mu \mathrm{M}$ or more resulted in complete inhibition of cell viability. As expected, A2780cp cells were more resistant to cisplatin than A2780s. In contrast to the results observed with A2780s, A2780-cp cells grown as nonadherent aggregates were more resistant to cisplatin than cells grown as monolayer cultures when treated with $20-50 \mu \mathrm{M}$ cisplatin. The differences were statistically significant $(p<0.05)$. The rightward shift in the $\mathrm{CC}_{50}$ concentration changed from $\sim 18 \mu \mathrm{M}$ to $27 \mu \mathrm{M}$.

The effect of cisplatin on viability was also investigated with the COV362 HGSOC cell line grown under adherent and non-adherent conditions. The results revealed a profile that was somewhat similar to the cisplatin sensitivity profile obtained with the A2780cp cells. Greater resistance to cisplatin was observed under non-adherent conditions, and a more dramatic shift in the $\mathrm{CC}_{50}$ from $\sim 11 \mu \mathrm{M}$ to $\sim 36 \mu \mathrm{M}$ (Additional file 5: Figure S4). At the highest concentration of cisplatin tested, $90 \mu \mathrm{M}, 25 \%$ of the cells were still viable. Thus, these cells are more resistant to cisplatin than A2780cp cells. 


\section{a}
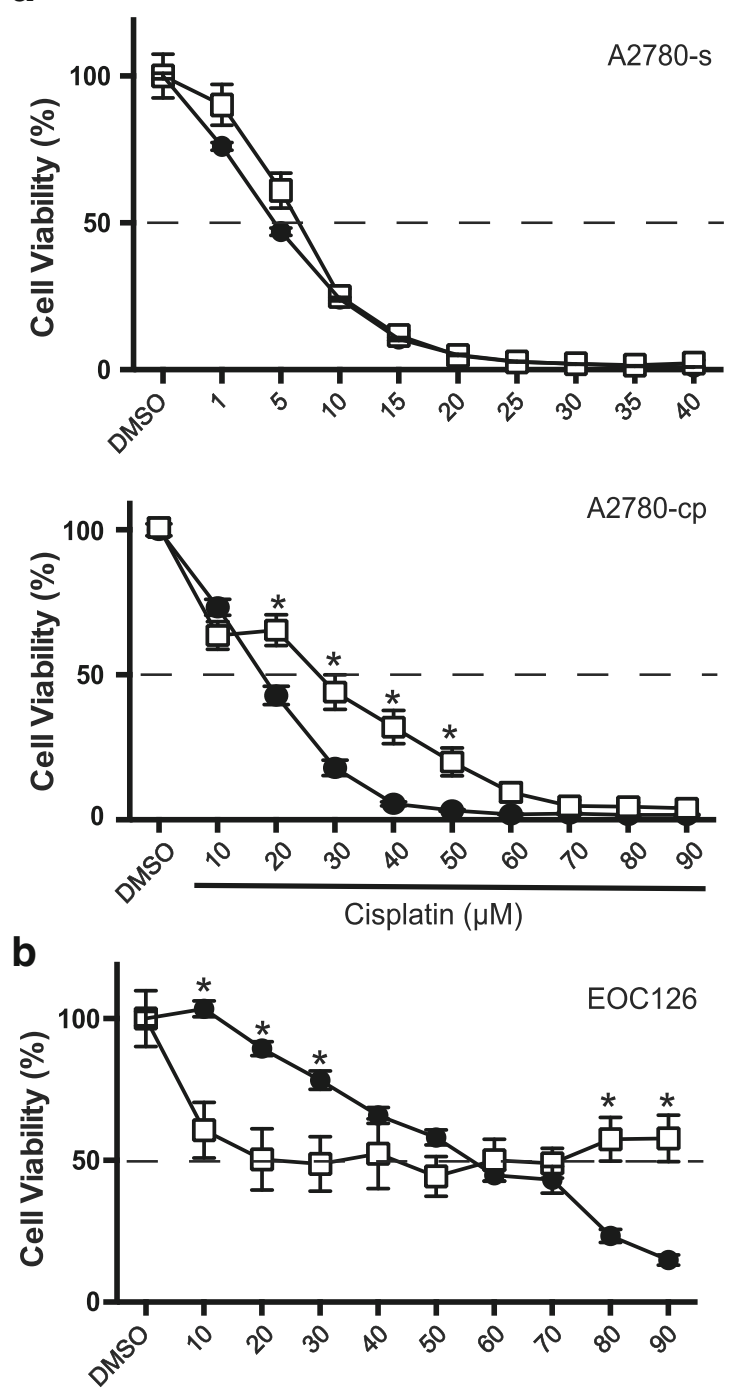

$\square$ - Non-adherent

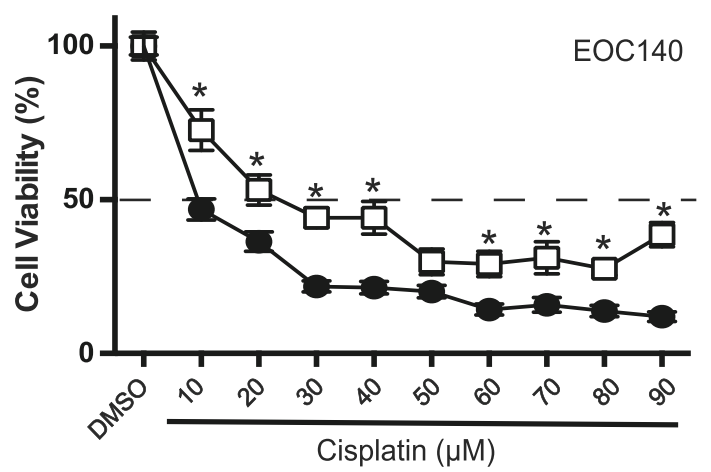

Fig. 1 Cisplatin sensitivity of EOC cells grown as adherent (closed circle) or non-adherent (open square) cultures. a Cisplatin dose-response curves for cisplatin-sensitive A2780-s and isogenic cisplatin-resistant A2780-cp cells. b Cisplatin dose-response curves for two different primary EOC patient samples, EOC126 and EOC 140. For A and B cells were exposed to drug for 72 h. Intersections with the dashed line approximates the $\mathrm{CC}_{50}$ value. Cisplatin doses where there is a significant difference in cell viability between cells grown as adherent or non-adherent cultures are indicated by an asterisk (*), $p<0.05$ 
The effects of cisplatin on the viability of primary cells isolated from EOC patient samples was also investigated (Fig. 1b). In EOC126 (clear cell histotype) grown as adherent cultures, a dose-dependent effect of cisplatin on the viability of the cells was observed with an $\mathrm{CC}_{50} \sim$ $57 \mu \mathrm{M}$ and viability down to $15 \%$ at $90 \mu \mathrm{M}$. By contrast, in EOC126 cells grown as non-adherent cultures, there was an initial response to cisplatin with cell viability down to $50 \%$ at a concentration of $20 \mu \mathrm{M}$. Further increases in cisplatin up to $90 \mu \mathrm{M}$ did not result in any further decrease in cell viability, but compared to monolayer cultures, non-adherent cultures exhibited a statistically significant difference in viability at $80-90 \mu \mathrm{M}$. Similarly, cell death in EOC140 cells (HGSOC histotype), which were obtained from a patient with recurrent, platinum-resistant disease, was dose-dependent up to $30 \mu \mathrm{M}$ using either culture condition, but further increases in cisplatin did not affect cell viability up to $90 \mu \mathrm{M}$ (Fig. 1b). Statistically significant differences in EOC140 cell viability between the adherent and non-adherent cells were observed with the cells grown under non-adherent conditions being more resistant to cisplatin.
Additional examples of differential cisplatin sensitivity when primary HGSOC cells (EOC 146, EOC183A, EOC183I) were grown as adherent or non-adherent aggregates are shown in Additional file 5: Figure S4.

\section{EOC cell response to GAEL treatment}

The EOC cell lines grown as non-adherent cultures showed dose-dependent decreases in cell viability when treated with either GLN or MO-101, with MO-101 typically having greater efficacy (Fig. 2). Cisplatin-sensitive A2780-s cells showed reduced cell viability in response to both GAELs (GLN CC $50 \sim 14 \mu \mathrm{M}$; MO-101 $\mathrm{CC}_{50} \sim$ $10 \mu \mathrm{M})$, but GLN was less effective than MO-101 at killing the cells at concentrations between 2.5-12.5 $\mu \mathrm{M}$. At doses above $12.5 \mu \mathrm{M}$, both GAELs had a similar effect on cell viability. The viability of cisplatin-resistant A2780-cp cells was also decreased with increasing concentrations of GLN and MO-101, with $\mathrm{CC}_{50} \sim 15 \mu \mathrm{M}$ for GLN and a $\mathrm{CC}_{50} \sim 9 \mu \mathrm{M}$ for MO-101. Similar to the observations with A2780s cells, MO-101 was more effective in killing the A2780-cp cells than GLN. Parallel
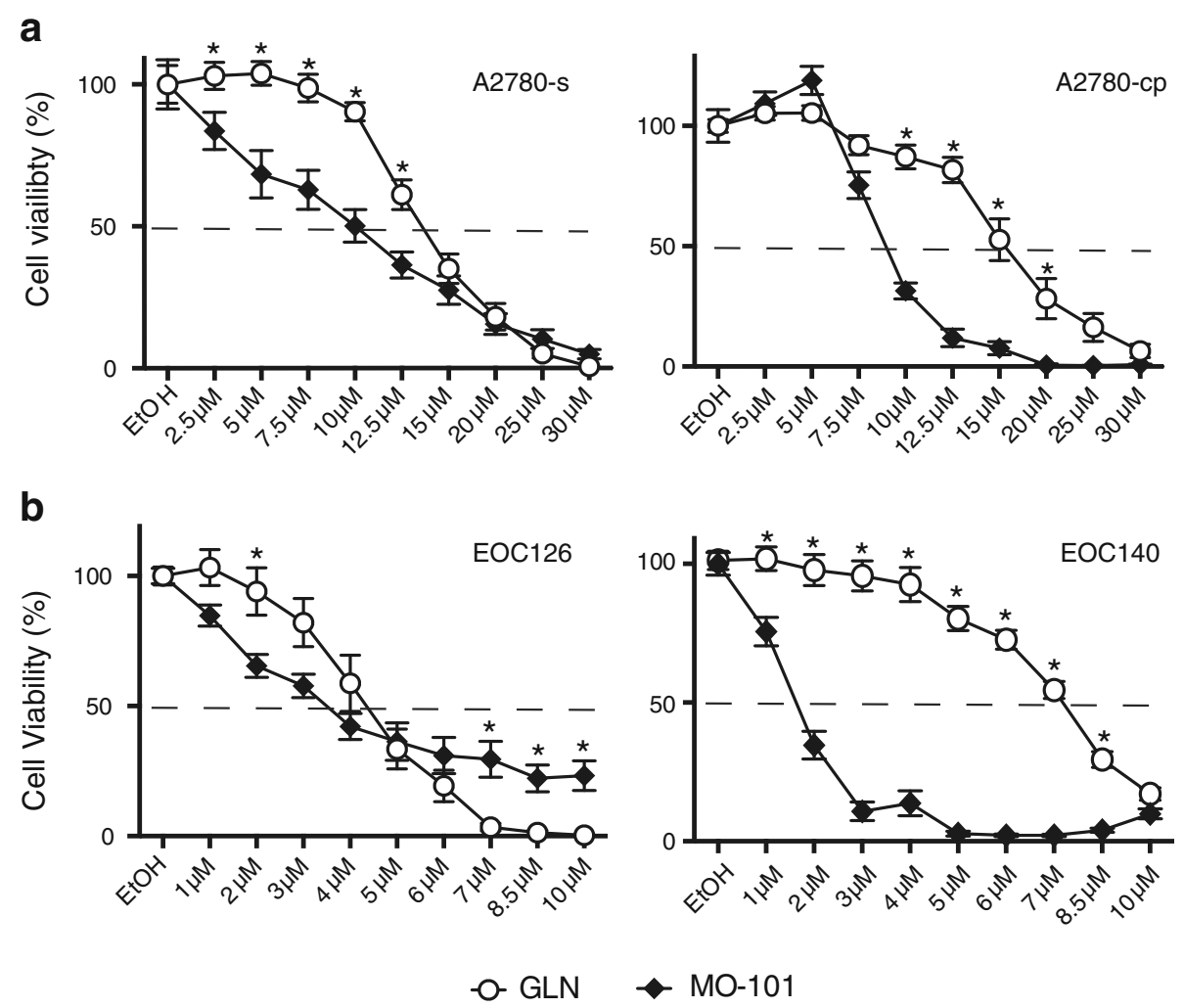

Fig. 2 GAEL sensitivity of EOC cells grown in the presence of GLN (open circle) or MO-101 (closed diamond). a Dose-response curves for A2780-s (cisplatin sensitive) and A2780-cp (cisplatin resistant) cells. b Dose-response curves to GLN or MO-101 for two different primary EOC patient samples, EOC126 and EOC140. For A and B cells were exposed to drug for $48 \mathrm{~h}$. Intersection with the dashed line approximates the $\mathrm{CC}_{50}$ value. Doses where there is a significant difference in cell viability between cells grown in the presence of GLN or MO-101 are indicated by an asterisk $(*), p<0.05$ 
studies using the COV362 HGSOC cell line showed resistance to GLN at doses up to $15 \mu \mathrm{M}$, but sensitivity thereafter (Additional file 6: Figure S5). By contrast, COV362 cells were sensitive to MO-101 at doses higher than $2.5 \mu \mathrm{M}$.

The effects of the GAELs on the viability of primary EOC cells isolated from patients was also investigated (Fig. 2 and Additional file 6: Figure S5). We observed that much lower doses of the GAELs were required to kill the cells from primary patient samples (EOC126 and EOC140; Fig. 2) compared to the A2780 cell lines. EOC126 cells that exhibited cisplatin resistance (Fig. 1) were effectively killed by GLN with a $\mathrm{CC}_{50}$ value of $4.3 \mu \mathrm{M}$. MO-101 was surprisingly unable to kill all the EOC126 cells at the highest concentration tested $(10 \mu \mathrm{M})$. A $\mathrm{CC}_{50}$ value of $3.5 \mu \mathrm{M}$ was obtained for MO101 , but at $10 \mu \mathrm{M} \sim 20 \%$ of the cells were still viable. By contrast, EOC140 cells were effectively killed by MO101, but showed some resistance to GLN-induced death. Additional examples of differential primary EOC cell (EOC 146, EOC183A, EOC183I) GAEL sensitivity are shown in (Additional file 6: Figure S5).

To extend these studies, primary cells were grown as adherent monolayer or spheroid cultures, and their response to MO-101 was compared (Fig. 3). Serial samples from the same patient were obtained prior to (EOC016B - chemonaive) and after (EOCO16H - platinum resistant) chemotherapy treatment. MO-101 effectively killed these samples and sample EOC058 (HGSOC; chemonaive) in a dose-dependent fashion, even when grown as spheroids (Fig. 3a). As well as assessing the viability of the cells, we also looked at the effect of the GAELs on the integrity of the spheroids. GAELs were able to cause the disintegration of the spheroids and a representative image of the disintegration of the spheroid from EOC058 cells in response to MO-101 treatment is shown (Fig. 3b). Similar results were obtained with two additional EOC samples (EOC013F, EOC061; Additional file 4: Figure S3).

These experiments showed that different patient samples exhibited differential sensitivity and cell proliferation responses to the GAEL compounds. Importantly, these results showed that GAEL compounds can effectively kill cisplatin-sensitive and cisplatin-resistant EOC cell lines and primary cells isolated from patient samples grown as adherent monolayers, aggregates, or spheroids using non-adherent culture conditions.

\section{Evaluating potential mechanisms of GAEL-induced EOC cell death}

To gain insight into how GAELs may be affecting EOC cell viability, cell cycle analysis by flow cytometry was conducted for A2780-cp cells using BrdU and 7AAD. We observed a shift towards sub-G0/G1, as cells exited the cell cycle in response to GAEL treatment and displayed an increase in cell death (Fig. 4a). In support of this, Annexin V/7AAD staining was conducted to measure A2780-cp cell death after GAEL treatment (Fig. 4b). A2780-cp cells exhibited a dose-dependent increase in dying and dead cells in response to GLN and MO-101 treatment for $48 \mathrm{~h}$, with the highest doses of GLN $(25 \mu \mathrm{M})$ and MO-101 $(15 \mu \mathrm{M})$ resulting in $~ 86 \%$ (upper quadrants, $33.4 \%+53.8 \%)$ and $70 \%(19.2 \%+53.7 \%)$ cell death, respectively.

\section{Pepstatin A did not rescue GAEL-induced EOC cell death}

Previous research demonstrated that GAELs induced an apoptosis-independent form of cancer cell death that may involve altering lysosomal permeability to allow the release of acid proteases such as cathepsin D [26]. GLN-induced cell death could be reduced, but not abrogated, by incubation of cells with the acid protease inhibitor pepstatin A. To investigate if a similar mechanism may operate in EOC cells, A2780-cp cells were incubated with GLN, MO-101, or the GAELs with pepstatin A. The results obtained revealed that neither GLN- or MO-101-induced cell death were attenuated by pepstatin A co-treatment (Fig. 5a). These data suggest that acid proteases such as cathepsin D do not play a role in GAEL-induced cell death in A2780-cp cells. The involvement of other cathepsins were not investigated and cannot be ruled out. A similar response was observed in EOC140 and EOC183A cells treated with MO-101 (Fig. 5b and Additional file 7: Figure S6a). By contrast, pepstatin A was capable of reducing the cell killing effects of MO-101 in the primary EOC146 cell sample at some dose combinations (Additional file 7 : Fig. 6b). In particular, protection was noted with the combination of $5 \mu \mathrm{M}$ MO- $101+30 \mu \mathrm{g} / \mathrm{mL}$ pepstatin A. However, the viability of the cells in the presence of pepstatin was still below that of the controls, an indication that protection by inhibiting cathepsin $\mathrm{D}$ was not complete. These data suggest that GAELs may induce a cell death pathway involving acid proteases that contribute to the overall loss of cell viability in some primary cell samples, but this is not a universal response of EOC cells to MO-101 and is likely not the only means by which MO-101induces cell death.

Although previous studies reported that GAELs did not kill cells by inducing apoptosis, the inability of pepstatin to attenuate GAEL effects in A2780-cp cells, led us to investigate whether activation of apoptosis could play a role in GAEL-induced cell death in these cells. A2780-cp cells were incubated with GLN or MO-101 and cell death was quantified with annexin $\mathrm{V}$ plus 7AAD staining. The results displayed in Fig. 6a show a dose-dependent increase in Annexin $\mathrm{V}$ positive dying and dead cells in response to GLN and MO-101 
a

\begin{tabular}{|c|c|c|c|c|c|c|}
\hline $\begin{array}{c}{[M O-101]} \\
\boldsymbol{\mu M}\end{array}$ & \multicolumn{2}{|c|}{ EOC016B } & \multicolumn{2}{c|}{ EOC016H } & \multicolumn{2}{c|}{ EOC058 } \\
\cline { 2 - 7 } & Adherent & Spheroid & \multicolumn{2}{c|}{ Adherent } & Spheroid & \multicolumn{2}{c|}{ Adherent } & Spheroid \\
\hline $\mathbf{0}$ & 100 & 100 & 100 & 100 & 100 & 100 \\
$\mathbf{0 . 1}$ & - & - & $71.8+/-6.9$ & - & - & - \\
$\mathbf{0 . 2}$ & - & - & $34.4+/-0.4$ & - & - & - \\
$\mathbf{0 . 2 5}$ & $49.9+/-6.1$ & $92.8+/-8.7$ & - & $33.7+/-3.3$ & $95.7+/-3.8$ & $92.4+/-89.6$ \\
$\mathbf{0 . 3}$ & - & - & 0 & - & - & - \\
$\mathbf{0 . 5}$ & $0.8+/-1.8$ & $73.8+/-3.7$ & - & 0 & $69.0+/-7.7$ & $62.3+/-5.8$ \\
$\mathbf{1}$ & 0 & $12.5+/-6.0$ & - & - & $4.4+/-2.2$ & 0 \\
$\mathbf{2}$ & - & $11.4+/-6.1$ & - & - & 0 & - \\
$\mathbf{3}$ & - & $6.4+/-6.3$ & - & - & - & - \\
$\mathbf{4}$ & - & $6.9+/-5.2$ & - & - & - & - \\
\hline
\end{tabular}

b

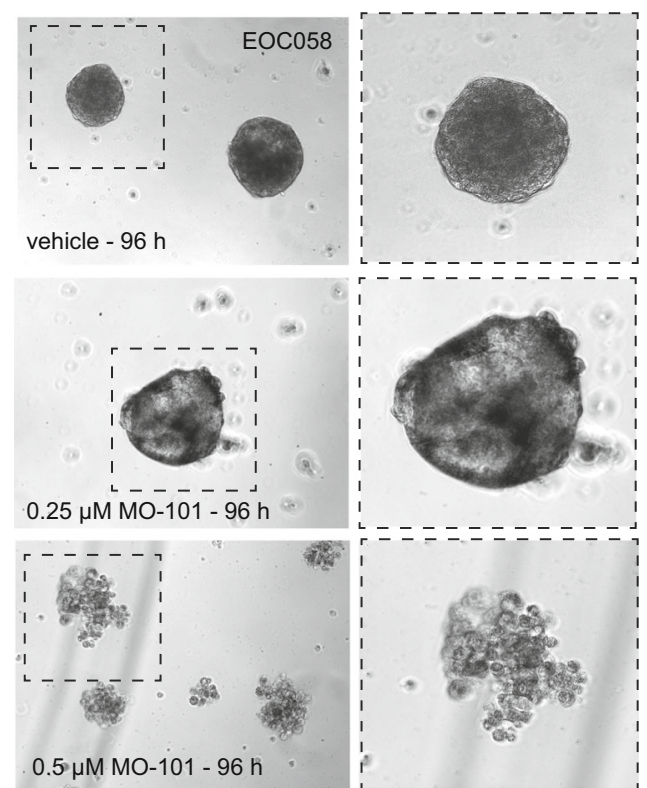

Fig. 3 GAEL sensitivity of EOC cells grown as spheroids. a MO-101 dose-response of primary EOC cell samples (EOC016B and H, EOC058). Cells were exposed to MO-101 for $72 \mathrm{~h}$ prior to determining cell viability. Data is shown as percent viability compared to vehicle treated controls. $\mathbf{b}$ Effect of MO-101 on EOC058 spheroid integrity after $96 \mathrm{~h}$ exposure. The right-hand panels show higher magnification images of the spheroids outlined by dashed boxes in the left panel

treatment for $48 \mathrm{~h}$. The highest doses of GLN $(25 \mu \mathrm{M})$ and MO-101 $(12.5 \mu \mathrm{M})$ resulted in up to $78 \%$ (upper quadrants, $42.4 \%+35.8 \%)$ or $\sim 36 \%(16.3 \%+19.3 \%)$ dead cells, respectively. The presence of dying/dead cells that stained for Annexin V suggested that GAELs may induce apoptosis in A2780-cp cells. To further investigate this, caspase activation in cells treated with GAELs was assessed. A2780-cp cells were treated for $48 \mathrm{~h}$ with $25 \mu \mathrm{M}$ GLN, $12.5 \mu \mathrm{M}$ MO-101, or $70 \mu \mathrm{M}$ cisplatin (as a positive control to induce caspase activity) and caspase activity was measured using the Caspglow assay. The results showed that there was an increase in caspase activity in response to each treatment (Fig. 6b). The percentage of viable cells at the conclusion of each experiment as determined by trypan blue dye exclusion assay revealed the GAEL-induced increase in caspase activity corresponded with a reduction in viable cells.

In order to test whether caspase activity was linked with the reduction in cell viability, A2780-cp cells were treated with GAELs in the presences of the pan-caspase inhibitor Q-VD-OPh (QVD). A2780-cp cells were pretreated with or without $25 \mu \mathrm{M}$ QVD for $4 \mathrm{~h}$ prior to the addition of the GAEL. In the GLN + QVD treated cells there was a 3.2-fold decrease in the number of dead cells compared to GLN-alone (Fig. 6a). In similar experiments conducted with non-adherent aggregate cultures, the percentage of viable cells as assessed by the CellTiter assay rose from $1 \%$ to about $20 \%$ in A2780-cp cells treated with GLN + QVD compared to GLN alone (Fig. 6c). Conflicting data was observed for MO-101 

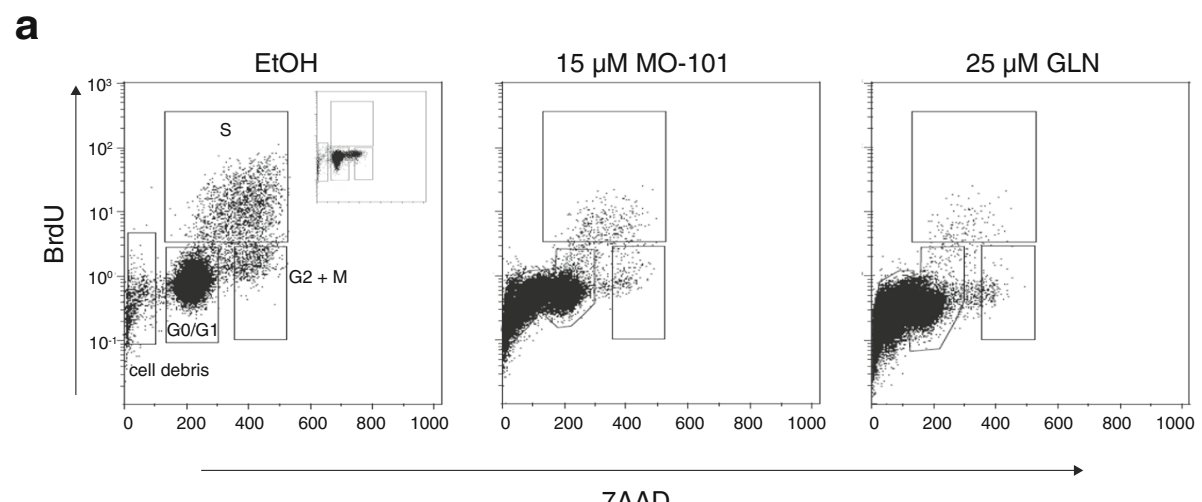

b

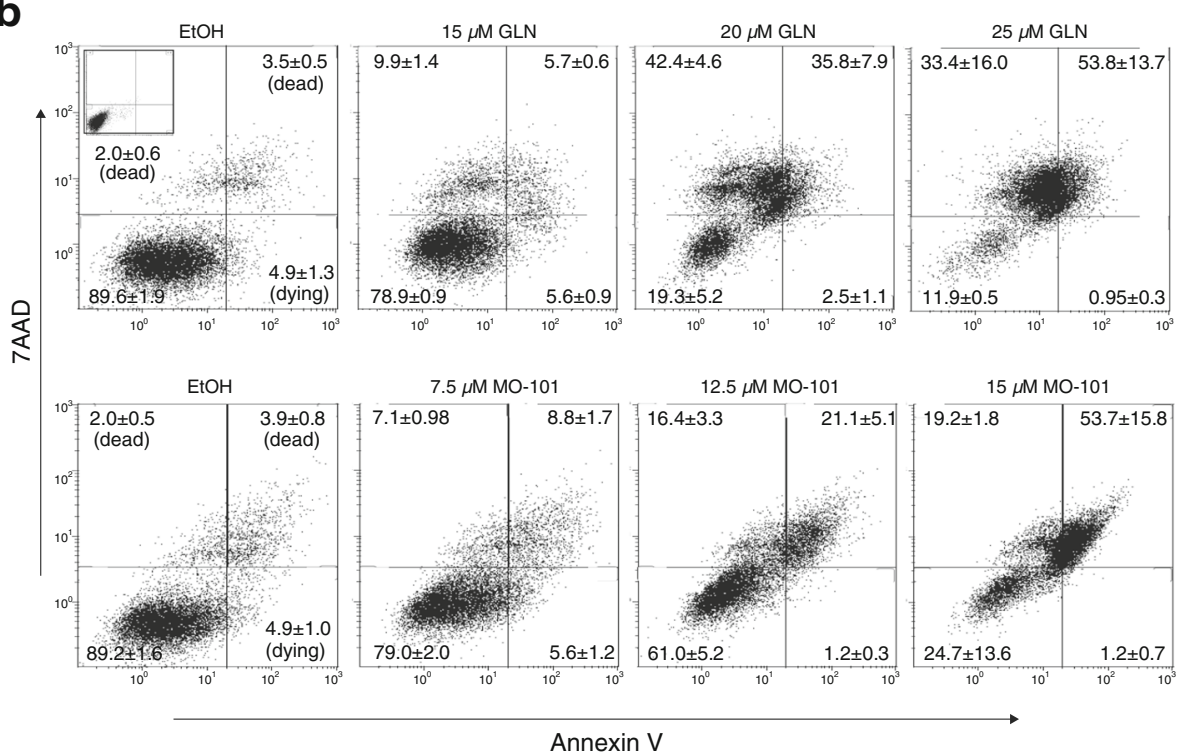

Fig. 4 Effect of GAEL to induce cell death. a BrdU/7AAD analysis of A2780-cp non-adherent cultures treated with GLN or MO-101 relative to ethanol (EtOH) controls after $48 \mathrm{~h}$. Data corresponding to cells at different stages of the cell cycle are indicated, as are dead (apoptotic; cell debris) cells. $\mathbf{b}$ Annexin V/7AAD analysis of A2780-cp non-adherent cultures treated with increasing doses of GLN or MO-101 relative to EtOH controls after $48 \mathrm{~h}$. Percentage of cells in each quadrant are indicated

treated cells. In the presence of MO-101+QVD, there was a 1.5 fold further increase in cell death compared to MO-101 alone (Fig. 6a). However, QVD reduced the amount of cell death induced by MO-101 using the CellTiter assay (Fig. 6c). These results support the notion that caspase activation occurs in A2780-cp cells in response to GAEL treatment, but pathways activated by the caspases are not solely responsible for cell death.

We next investigated whether inhibition of caspase activity in primary EOC cells would rescue the cells from GAEL-induced cell death using the approaches described above. Studies with EOC126 or EOC146 cells showed that pre-incubation with QVD prior to the addition of MO-101 did not result in an increase in viability relative to cells incubated with MO-101 alone (Fig. 6d;
GLN was not tested on the primary EOC cell samples for this assay). Similar results were obtained for EOC183A (Additional file 8: Figure S7). It was notable that QVD treatment alone was capable of increasing the number of viable cells in EOC126 and EOC146, suggesting that there is a basal level of activated caspases in the EOC cells. As a positive control for these experiments, the effect of QVD on cisplatininduced cell death, which is known to occur via caspase activation, was investigated. Cisplatin-induced caspase activity was efficiently blocked by pretreatment with QVD (Fig. 6d and Additional file 8: Figure S7). Thus, in primary EOC cells GAELinduced cell death appeared to be completely caspaseindependent. 


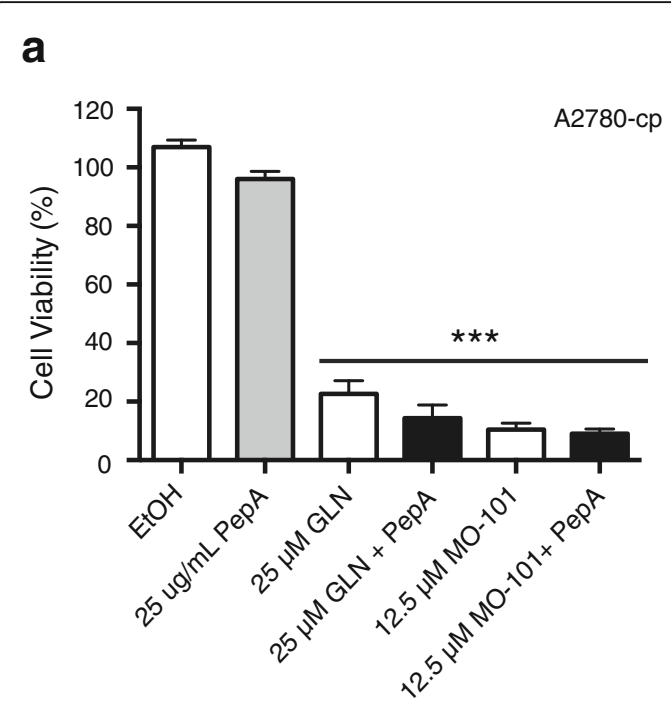

b

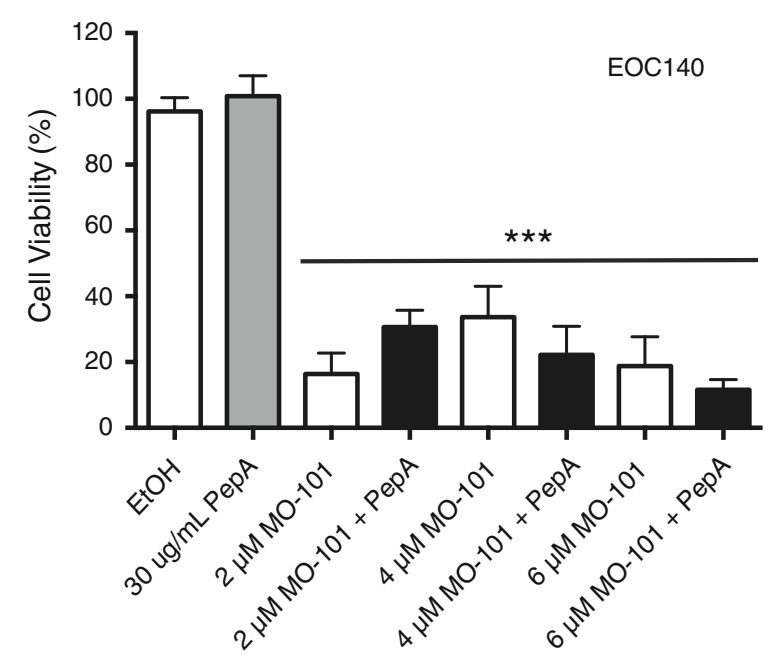

Fig. 5 Evaluating the ability of pepstatin $A$ (PepA) to block GAELinduced cell death. a A2780-cp cells were treated with GLN or MO101 alone or co-treated with $25 \mu \mathrm{g} / \mathrm{mL}$ PepA for $48 \mathrm{~h}$. While GAEL or GAEL + PepA treatment induced a significant level of cell death, there was no statistical difference in the presence of PepA. $\mathbf{b}$ EOC140 cells treated with increasing doses of MO-101 alone or cotreated with $30 \mu \mathrm{g} / \mathrm{mL}$ PepA for $48 \mathrm{~h}$. There is a statistically significant inhibition of cell death in the presence of PepA for two of the conditions, $(+), p<0.05$. For both $A$ and $B$, doses where there is a significant difference in cell viability between cells grown in the presence of drugs compared to vehicle control or PepA alone are indicated by asterisks (***), $p<0.001$

\section{Discussion and conclusions}

There is an urgent need for novel drugs to effectively treat recurrent, drug-resistant EOC. Herein we show that GAELs effectively kill platinum-sensitive and platinum-resistant EOC cell lines and primary EOC cell samples in adherent and non-adherent culture systems. Cells grown as non-adherent cultures typically represent a more drug-resistant profile compared to monolayer cultures $[9,14-16]$. The non-adherent culture conditions approximate cells growing as ascites in vivo. It was therefore important to test the cell killing effect of the anticancer drugs in vitro using the non-adherent culture conditions to obtain a better idea of possible responses in vivo. The data reported herein suggest that GAELs may constitute a novel drug class with potential for effectively treating different EOC histotypes, and more importantly platinum-resistant cells commonly found with recurrent EOC.

Our work confirms earlier reports showing enhanced cisplatin resistance of EOC cells when grown as non-adherent cultures relative to cell monolayers $[9,14,15,34]$, with some non-adherent cultures showing resistance to cisplatin up to the maximum dose tested $(90 \mu \mathrm{M})$. By contrast, we showed that GAELs are effective at killing EOC cells grown as adherent monolayers, non-adherent cellular aggregates, or as spheroids at much lower concentrations. Depending on the assay used, this required exposure to the drugs for different time courses (48 h to test cell viability; 72-96 h when examining spheroid dissolution). Notably, the doses of GAELs required to kill EOC cells were a fraction of the cisplatin doses required to kill the same cells. GAELs effectively killed EOC cells from several primary HGSOC samples, a HGSOC cell line (COV362), as well as a primary clear cell EOC sample (EOC126), and an endometrioid EOC cell line (A2780).

For primary cells grown as non-adherent cultures, the dose of cisplatin needed to kill these cells was not attained within the dose range used, but were in excess of those required to kill the A2780-cp cisplatin resistant cell line. Relative resistance to MO-101 was observed in EOC126 and resistance to GLN in EOC140, EOC146, and EOC183 primary cell cultures. However, it is worth pointing out that the highest concentration of GAEL tested was $10 \mu \mathrm{M}$, and therefore it remains possible that complete cell death may have been achieved at higher concentrations. The reason why the different cells are susceptible to one GAEL and not the other is unclear but may reflect an inherent property of the EOC histotype (i.e. EOC126 are clear cell; the other primary samples are high grade serous), or genetic changes within that patient sample. GLN and MO-101 are structurally similar but are differentially charged as a consequence of the additional amino group on MO-101 relative to GLN. Noteworthy is the fact that all the EOC cells were susceptible to one GAEL or the other.

Experiments were conducted to investigate potential mechanism(s) of action for GAEL-induced cell death. Previous reports showed that GAELs induce a caspaseindependent form of cell death, part of which was due to the release of acid proteases such as cathepsin D 
a

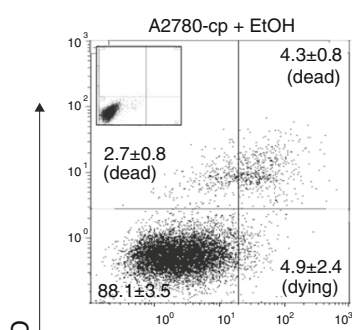

这

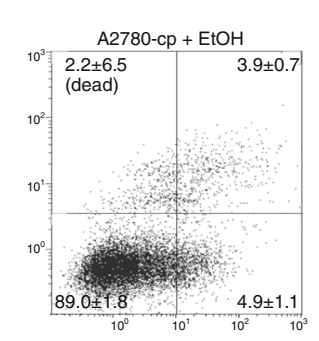

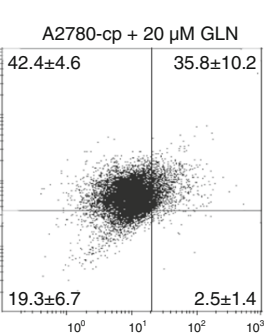

$\mathrm{A} 2780-\mathrm{cp}+20 \mu \mathrm{M}$ GLN

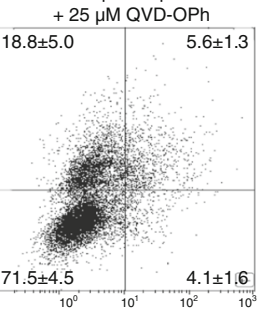

A2780-cp + $12.5 \mu \mathrm{M}$ MO-101

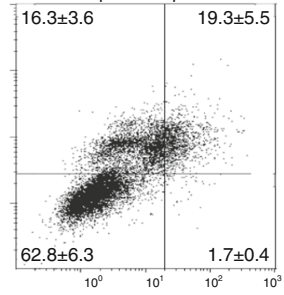

A2780-cp + 12.5 uM MO-101 $+25 \mu \mathrm{M}$ QVD-OPh

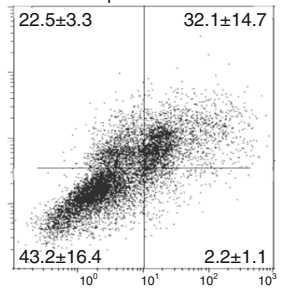

Annexin V

b

\begin{tabular}{|c|c|c|}
\hline A2780-cp & $\begin{array}{c}\text { Fold increase } \\
\text { (caspase activity) }\end{array}$ & Viable cells \\
\hline $25 \mu \mathrm{M}$ GLN & $19.2+/-14.3$ & $72 \%$ \\
\hline $12.5 \mu \mathrm{M}$ MO-101 & $11.3+/-4.2$ & $43 \%$ \\
\hline $70 \mu \mathrm{M}$ cisplatin & $19.0+/-11.7$ & $61 \%$ \\
\hline
\end{tabular}

c

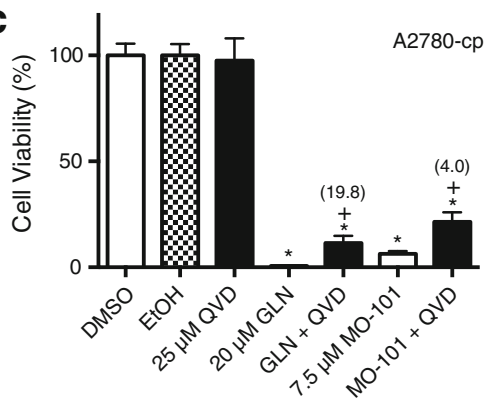

d

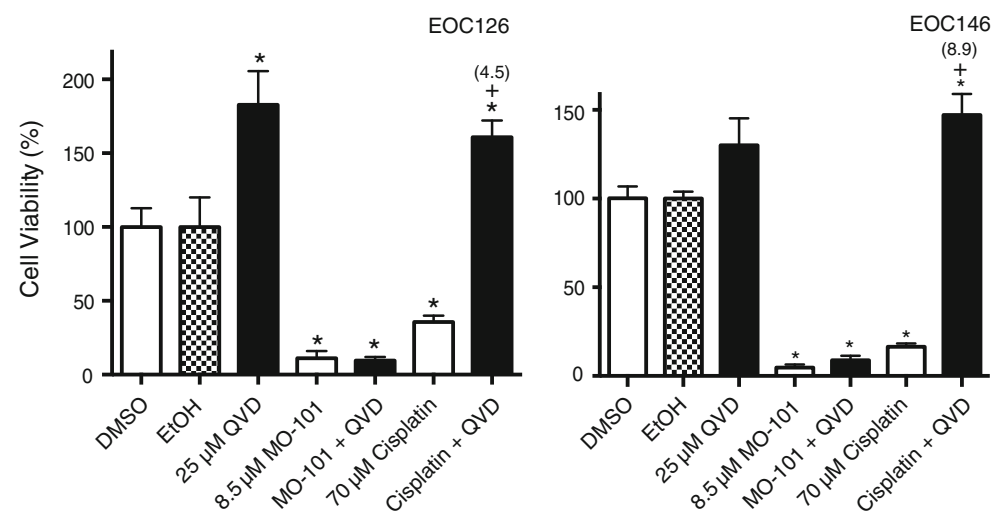

Fig. 6 (See legend on next page.) 
(See figure on previous page.)

Fig. 6 Examining the role of caspases for GAEL-induced cell death. a Viability of A2780-cp cells treated with GAELs alone or pretreated with the pan-caspase inhibitor Q-VD-OPh (QVD) for 4 h, prior to co-treatment with GAELs and QVD for 48 h. Percentage of cells in each quadrant are indicated. b Activated caspases were measured in A2780-cp cells $24 \mathrm{~h}$ after initiation of treatment with GLN, MO-101, or cisplatin. Fold caspase activity in comparison to vehicle control treated cells is indicated. Percent viability at the time of cell harvest is indicated as measured by trypan blue exclusion. c Viability of A2780-cp cells treated with GAELs alone or pretreated with the pan-caspase inhibitor Q-VD-OPh (QVD) for $4 \mathrm{~h}$, prior to co-treatment with GAELs and QVD for $48 \mathrm{~h}$. The fold increase in cell viability is shown in co-treated cells, indicated in brackets above the bar. ${ }^{*}$ significantly different from vehicle control; + significantly different from GAEL alone; $p<0.005$. d Viability of primary EOC cell samples, EOC126 or EOC146, treated with GAELs alone or pretreated with the pan-caspase inhibitor QVD. No significant difference in cell viability was observed in the presence of QVD, with the exception of the cisplatin positive control. * significantly different from vehicle control; + significantly different from cisplatin alone; $p<0.005$

from the lysosomes into the cytosol [23, 28]. While pepstatin A, an inhibitor of cathepsin D, did not affect GAELinduced death in A2780-cp, EOC140, or EOC183A cells, a protective effect was observed in EOC146 cells. This suggests that the involvement of cathepsin $\mathrm{D}$ to cell death may occur in some EOC patient samples, but is not be a universal event in all EOC cells.

In A2780-cp cells, GAELs induced the activation of caspases, and the increased caspase activity that correlated with reduced cell viability was partially blocked by the pan-caspase inhibitor (QVD). This was consistent for GLN, but MO-101 produced contrasting results. The presence of QVD had no effect on MO-101-induced cell death, and in fact enhanced the amount of cell death, when tested using flow cytometry. However, there was a reduction in cell death when tested using the CellTiter assay. These different results may be a reflection of the sensitivity of the different assays to the level of cell death, or it may reflect the different culture condition used for each assay. CellTiter experiments were conducted using a 96-well format, whereas the flow cytometry experiments required generation of cell aggregates and drug treatment in several wells of a 12-well plate. The flow cytometry experiments required a greater number of cells, and thus several wells were pooled for a single condition.

GLN and MO-101-induced cell death appears to be partially dependent on caspase activity in A2780-cp cells. By contrast, the presence of QVD had no effect on MO-101induced death in primary EOC cells. These results are similar to our previous results using different cancer cell types and other GAELs [28]. Thus, in EOC cells, GAELinduced cell death is primarily via a caspase-independent mechanism that may be augmented by caspase activation in A2780-cp cells. One beneficial effect of this is that if the apoptosis pathway is inhibited in the cancer cell, cell death may still occur via the caspase-independent mechanisms. Additional research is required to illuminate the mechanisms of cell death induced by GAEL compounds. The overall conclusion from our studies is that GAELs in general, and MO-101 in particular, will be an excellent lead agent for in vivo assessment of its efficacy against platinum-resistant ovarian cancer. While in vivo studies have not been conducted with these compounds, future studies are planned to investigate the tolerability and efficacy of GAELs, and MO-101 in particular, for treating EOC in vivo.

\section{Additional files}

Additional file 1: Table S1. Primary EOC patient sample histological diagnosis, surgical staging and/or chemotherapy resistance status, and CA-125 levels at time of cell sampling.

Additional file 2: Figure S1. Chemical structure of GLN and MO-101. Note the amino substitution at the $\mathrm{C}_{6}$-position of glucose in MO-101.

Additional file 3: Figure S2 a. Images of ovarian cancer cell clusters present in ascites fluid from patients EOC174 and EOC189. EOC174 had a larger number of cell clusters and larger clusters resembling spheroids. b. Representative images of EOC cells (A2780-cp cell line or primary cell samples EOC140 and EOC146) grown as adherent monolayers, non-adherent aggregates or spheroids at 2 and 7 days after seeding ultralow attachment plates. EOC140 are capable of forming spheroids by 7 days after seeding, whereas EOC146 formed numerous spheroid structures within 2 days.

Additional file 4: Figure S3. Effect of MO-101 on spheroid integrity. Spheroids from EOC013F and EOC061 were exposed to increasing doses of MO-101. Spheroid integrity was observed after $72 \mathrm{~h}$ of drug exposure. Spheroid disintegration is observed with increasing doses. The grainy material in some panels is cellular debris.

Additional file 5. Figure S4. Drug sensitivity of COV362 HGSOC cell line, and three primary HGSOC patient samples. Cisplatin dose-response curves for COV362, EOC146, EOC183A, EOC183I cells grown as adherent (closed circle) or non-adherent (open square) cultures. Intersections with the dashed line approximates the $\mathrm{CC}_{50}$ value. Drug doses where there is a significant difference in cell viability between culture conditions or treatments are indicated by an asterisk $(*), p<0.05$.

Additional file 6: Figure S5. Dose-response curves for COV362 cells and three primary HGSOC patient samples (EOC146, EOC183A, EOC183I) to GLN (open circle) or MO-101 (closed diamond). Intersections with the dashed line approximates the $\mathrm{CC}_{50}$ value. Drug doses where there is a significant difference in cell viability between culture conditions or treatments are indicated by an asterisk $(*), p<0.05$.

Additional file 7: Figure S6. Evaluating the ability of pepstatin A (PepA) to block GAEL-induced cell death in EOC140 cells. a. EOC183A cells were treated with increasing doses of MO-101 alone or co-treated with $25 \mathrm{\mu g} / \mathrm{mL}$ PepA for 48 h. While MO-101 or MO-101 + PepA treatment induced a significant level of cell death, there was no statistically significant rescue from cell death in the presence of PepA. b. EOC146 cells were treated with $5 \mu \mathrm{M}$ MO-101 alone or co-treated with 20 or $30 \mu \mathrm{g} / \mathrm{mL}$ PepA for $48 \mathrm{~h}$. There was a statistically significant increase in cell viability for cells treated with MO-101 + $30 \mu \mathrm{g} / \mathrm{mL}$ PepA compared to MO-101 alone (+). For both A and $B$ doses where there is a significant difference in cell viability between cells grown in the presence of drugs compared to vehicle control or PepA alone are indicated by asterisks $\left(^{* * *}\right), p<0.001$. 
Additional file 8: Figure S7. Viability of primary EOC183A cells treated with GAELs alone or pretreated with the pan-caspase inhibitor QVD. No significant difference in cell viability was observed in the presence of QVD, with the exception of the cisplatin positive control. * significantly different from vehicle control; + significantly different from cisplatin alone; $p<0.005$.

\section{Acknowledgements}

Not applicable.

\section{Funding}

This work was supported through a joint grant to MWN, GA, and FS from CancerCare Manitoba; and synthesis of the GAELs was supported by a grant to FS, NSERC-DG (261311-2013). AIM was funded by the Saudi Arabian Cultural Bureau in Canada. LL was supported by a Research Manitoba Graduate Studentship. TEW received support from the Canada Research Chair Tier II program. Additional support to MWN was provided by a donation from Investors Group on behalf of J. Regehr.

\section{Availability of data and materials}

All data generated or analysed during this study are included in this published article [and its supplementary information files].

\section{Authors' contributions}

AIM helped conceptualize the project and contributed to the majority of the cell viability experiments. JLA contributed to experiments appearing in all Figures and additional files. PS conducted the spheroid experiments. $L L$ and LCM conducted the flow cytometry experiments. TWO interpreted the flow cytometry data, developed figures for this data, and co-wrote the article. MO and FS synthesized GLN and MO-101, and FS co-wrote the article. GA and MWN conceptualized the project, interpreted all data, and co-wrote the article. All authors read and approved the final manuscript.

\section{Competing interests}

The authors declare that they have no competing interests.

\section{Consent for publication}

Not applicable.

\section{Ethics approval and consent to participate}

Institutional approval for research with human materials was received prior to the initiation of these studies (University of Manitoba Human Research Ethics Board, \#HS166608), and samples were obtained after receiving Informed Patient Consent (University of Manitoba Human Research Ethics Board, \#HS11244).

\section{Publisher's Note}

Springer Nature remains neutral with regard to jurisdictional claims in published maps and institutional affiliations.

\section{Author details}

'Dept. of Biochemistry \& Medical Genetics, University of Manitoba, Room 333 BMSB, 745 Bannatyne Avenue, Winnipeg R3E 0 W9, MB, Canada. ${ }^{2}$ Dept. of Chemistry, University of Manitoba, Winnipeg, Canada. ${ }^{3}$ Dept. of Obstetrics, Gynecology \& Reproductive Sciences, University of Manitoba, Winnipeg, Canada. ${ }^{4}$ Research Institute in Oncology \& Hematology, CancerCare Manitoba, Winnipeg, Canada. ${ }^{5}$ Manitoba Ovarian Cancer Outcome (MOCO) study group, Winnipeg, Canada.

Received: 6 February 2017 Accepted: 8 May 2017 Published online: 12 May 2017

\section{References}

1. Bowtell DD, Bohm S, Ahmed AA, Aspuria PJ, Bast Jr RC, Beral V, Berek JS, Birrer MJ, Blagden S, Bookman MA, et al. Rethinking ovarian cancer II: reducing mortality from high-grade serous ovarian cancer. Nat Rev Cancer. 2015;15(11):668-79.

2. Coleman RL, Monk BJ, Sood AK, Herzog TJ. Latest research and treatment of advanced-stage epithelial ovarian cancer. Nat Rev Clin Oncol. 2013;10(4):211-24.
3. Patch AM, Christie EL, Etemadmoghadam D, Garsed DW, George J, Fereday S, Nones K, Cowin P, Alsop K, Bailey PJ, et al. Whole-genome characterization of chemoresistant ovarian cancer. Nature. 2015;521(7553):489-94.

4. Sherman-Baust CA, Becker KG, Wood lii WH, Zhang Y, Morin PJ. Gene expression and pathway analysis of ovarian cancer cells selected for resistance to cisplatin, paclitaxel, or doxorubicin. J ovarian res. 2011;4(1):21.

5. Suh DH, Kim MK, No JH, Chung HH, Song YS. Metabolic approaches to overcoming chemoresistance in ovarian cancer. Ann N Y Acad Sci. 2011; 1229:53-60.

6. Hiss D. Optimizing molecular-targeted therapies in ovarian cancer: the renewed surge of interest in ovarian cancer biomarkers and cell signaling pathways. J Oncol. 2012;2012:737981.

7. Cunnea P, Stronach EA. Modeling platinum sensitive and resistant highgrade serous ovarian cancer: development and applications of experimental systems. Front Oncol. 2014:4:81.

8. Friedrich J, Seidel C, Ebner R, Kunz-Schughart LA. Spheroid-based drug screen: considerations and practical approach. Nat Protoc. 2009;4(3):309-24.

9. Lee JM, Mhawech-Fauceglia P, Lee N, Parsanian LC, Lin YG, Gayther SA, Lawrenson K. A three-dimensional microenvironment alters protein expression and chemosensitivity of epithelial ovarian cancer cells in vitro. Lab Invest. 2013; 93(5):528-42.

10. Ashworth A, Balkwill F, Bast RC, Berek JS, Kaye A, Boyd JA, Mills G, Weinstein JN, Woolley K, Workman P. Opportunities and challenges in ovarian cancer research, a perspective from the 11th Ovarian cancer action/HHMT Forum, Lake Como, March 2007. Gynecol Oncol. 2008;108(3):652-7.

11. Kenny HA, Lal-Nag M, White EA, Shen M, Chiang CY, Mitra AK, Zhang Y, Curtis M, Schryver EM, Bettis S, et al. Quantitative high throughput screening using a primary human three-dimensional organotypic culture predicts in vivo efficacy. Nat Commun. 2015;6:6220.

12. Lengyel E, Burdette JE, Kenny HA, Matei D, Pilrose J, Haluska P, Nephew KP, Hales DB, Stack MS. Epithelial ovarian cancer experimental models. Oncogene. 2014:33(28):3619-33.

13. Zietarska M, Maugard CM, Filali-Mouhim A, Alam-Fahmy M, Tonin PN, Provencher DM, Mes-Masson AM. Molecular description of a 3D in vitro model for the study of epithelial ovarian cancer (EOC). Mol Carcinog. 2007; 46(10):872-85.

14. Chen J, Wang J, Chen D, Yang J, Yang C, Zhang Y, Zhang H, Dou J. Evaluation of characteristics of CD44 + CD117+ ovarian cancer stem cells in three dimensional basement membrane extract scaffold versus two dimensional monocultures. BMC Cell Biol. 2013;14:7.

15. Dong Y, Tan OL, Loessner D, Stephens C, Walpole C, Boyle GM, Parsons PG, Clements JA. Kallikrein-related peptidase 7 promotes multicellular aggregation via the alpha(5) beta (1) integrin pathway and paclitaxel chemoresistance in serous epithelial ovarian carcinoma. Cancer Res. 2010;70(7):2624-33.

16. Yang Z, Zhao X. A 3D model of ovarian cancer cell lines on peptide nanofiber scaffold to explore the cell-scaffold interaction and chemotherapeutic resistance of anticancer drugs. Int J Nanomedicine. 2011;6:303-10.

17. Colombo PE, Fabbro M, Theillet C, Bibeau F, Rouanet P, Ray-Coquard I. Sensitivity and resistance to treatment in the primary management of epithelial ovarian cancer. Crit rev oncol/hematol. 2014;89(2):207-16.

18. Howell SB, Safaei R, Larson CA, Sailor MJ. Copper transporters and the cellular pharmacology of the platinum-containing cancer drugs. Mol Pharmacol. 2010;77(6):887-94.

19. Latifi A, Luwor RB, Bilandzic M, Nazaretian S, Stenvers K, Pyman J, Zhu H, Thompson EW, Quinn MA, Findlay JK, et al. Isolation and characterization of tumor cells from the ascites of ovarian cancer patients: molecular phenotype of chemoresistant ovarian tumors. PLoS One. 2012;7(10): e46858.

20. Li M, Balch C, Montgomery JS, Jeong M, Chung JH, Yan P, Huang TH, Kim $\mathrm{S}$, Nephew KP. Integrated analysis of DNA methylation and gene expression reveals specific signaling pathways associated with platinum resistance in ovarian cancer. BMC Med Genet. 2009:2:34

21. Liao J, Qian F, Tchabo N, Mhawech-Fauceglia P, Beck A, Qian Z, Wang X, Huss WJ, Lele SB, Morrison CD, et al. Ovarian cancer spheroid cells with stem cell-like properties contribute to tumor generation, metastasis and chemotherapy resistance through hypoxia-resistant metabolism. PLoS One. 2014;9(1):e84941.

22. Vaughan S, Coward JI, Bast Jr RC, Berchuck A, Berek JS, Brenton JD, Coukos G, Crum CC, Drapkin R, Etemadmoghadam D, et al. Rethinking ovarian cancer: recommendations for improving outcomes. Nat Rev Cancer. 2011; 11(10):719-25. 
23. Arthur G, Bittman R. Glycosylated antitumor ether lipids: activity and mechanism of action. Anti Cancer Agents Med Chem. 2014;14(4):592-606.

24. Brachwitz $H$, Vollgraf C. Analogs of alkyllysophospholipids: chemistry, effects on the molecular level and their consequences for normal and malignant cells. Pharmacol Ther. 1995;66(1):39-82.

25. Erukulla RK, Zhou X, Samadder P, Arthur G, Bittman R. Synthesis and evaluation of the antiproliferative effects of 1-O-hexadecyl-2-0-methyl-3-O(2'-acetamido-2'-deoxy-beta-D- glucopyranosyl)-sn-glycerol and 1-0hexadecyl-2-0-methyl-3-0- (2'-amino-2'-deoxy-beta-D-glucopyranosyl)-snglycerol on epithelial cancer cell growth. J Med Chem. 1996;39(7):1545-8.

26. Jahreiss L, Renna M, Bittman R, Arthur G, Rubinsztein DC. 1-O-Hexadecyl-2 O-methyl-3-O-(2'-acetamido-2'-deoxy-beta-D-glucopyranosyl)-sn-gly cerol (GIn) induces cell death with more autophagosomes which is autophagyindependent. Autophagy. 2009;5(6):835-46.

27. Samadder P, Bittman R, Byun HS, Arthur G. A glycosylated antitumor ether lipid kills cells via paraptosis-like cell death. Biochemi cell biol = Biochim biol cell. 2009;87(2):401-14

28. Samadder P, Xu Y, Schweizer F, Arthur G. Cytotoxic properties of d-gluco-, d-galacto- and d-manno-configured 2-amino-2-deoxy-glycerolipids against epithelial cancer cell lines and BT-474 breast cancer stem cells. Eur J Med Chem. 2014;78:225-35.

29. Beaufort CM, Helmijr JC, Piskorz AM, Hoogstraat M, Ruigrok-Ritstier K, Besselink N, Murtaza M, van IWF, Heine AA, Smid M, et al. Ovarian Cancer Cell Line Panel (OCCP): Clinical Importance of In Vitro Morphological Subtypes. PLoS One. 2014;9(9):e103988.

30. Louie KG, Behrens BC, Kinsella TJ, Hamilton TC, Grotzinger KR, McKoy WM Winker MA, Ozols RF. Radiation survival parameters of antineoplastic drugsensitive and -resistant human ovarian cancer cell lines and their modification by buthionine sulfoximine. Cancer Res. 1985;45(5):2110-5.

31. Shepherd TG, Theriault BL, Campbell EJ, Nachtigal MW. Primary culture of ovarian surface epithelial cells and ascites-derived ovarian cancer cells from patients. Nat Protoc. 2006;1(6):2643-9.

32. Theriault BL, Portelance L, Mes-Masson AM, Nachtigal MW. Establishment of primary cultures from ovarian tumor tissue and ascites fluid. Methods Mol Biol. 2013;1049:323-36.

33. Ogunsina M, Samadder $P$, Idowu T, Arthur $G$ and Schweizer F. Design, synthesis and evaluation of cytotoxic properties of bisamino glucosylated antitumor ether lipids against cancer cells and cancer stem cells. Med Chem Commun. 2016:7:2100-10. doi.10.1039/C6MD00328A.

34. Loessner D, Stok KS, Lutolf MP, Hutmacher DW, Clements JA, Rizzi SC. Bioengineered 3D platform to explore cell-ECM interactions and drug resistance of epithelial ovarian cancer cells. Biomaterials. 2010;31(32):8494-506.

\section{Submit your next manuscript to BioMed Central and we will help you at every step:}

- We accept pre-submission inquiries

- Our selector tool helps you to find the most relevant journal

- We provide round the clock customer support

- Convenient online submission

- Thorough peer review

- Inclusion in PubMed and all major indexing services

- Maximum visibility for your research

Submit your manuscript at www.biomedcentral.com/submit 